Vol 13, Issue 6, 2020

\title{
A RETROSPECTIVE STUDY ON DRUG UTILIZATION PATTERN OF POISONING CASES ADMITTED IN A TERTIARY CARE TEACHING HOSPITAL
}

\author{
PRASANAND SASIDHARAN* \\ Department of Pharmacology, Dr. Somervell Memorial CSI Medical College, Thiruvananthapuram, Kerala, India. Email: prashrid@gmail.com
} Received: 09 March 2020, Revised and Accepted: 05 April 2020

\begin{abstract}
Objective: Poisoning with suicidal intention is a serious health issue among adults. Poisoning, as an emergency, is more common in India due to the easy availability of poisons, increased use of chemicals in industrial and domestic purposes. The objective of the study is to evaluate the nature of
\end{abstract} poisoning cases and the drug utilization pattern of poisoning cases.

Methods: A medical record-based retrospective data collection was conducted over a period of 21/2 years. Each prescription was analyzed by the demographic profile, the manner of poisoning (accidental or suicidal), the number of pharmacological agents causing poisoning, and type or name of the pharmacological agent responsible for the poisoning.

Results: Among 127 total patients, 113 cases were suicidal. Systemic poisons (47.24\%) were more consumed in our study, among which benzodiazepines (16.54\%) being the most common sub-class ingested. Of the 862 medications prescribed, normal saline (38.97\%) was the most commonly infused intravenous fluid. Gastric lavage (38.1\%) has been the most frequently used general measures. Injection pantoprazole (50.6\%) was the commonly prescribed anti-ulcer drug. The most commonly used analgesic (47.83\%) was paracetamol, antimicrobial agent was cefotaxime (25\%), Vitamin and minerals were Vitamin B complex (68\%), steroid was hydrocortisone (76\%), and antidote was atropine (37.5\%).

Conclusion: The magnitude of poisoning was high for suicidal purposes, in the young age group and in females. Intravenous fluids and general measures were the mainstay of the management of poisoned cases. Educational programs with an emphasis on preventive measures for toxic exposures are necessary to create awareness and to construct preventive strategies. Suggestions like poisoning centers in tertiary care hospitals will also help decrease morbidity and mortality.

Keywords: Drug utilization, Suicidal, Manner of poisoning.

(C) 2020 The Authors. Published by Innovare Academic Sciences Pvt Ltd. This is an open access article under the CC BY license (http://creativecommons. org/licenses/by/4. 0/) DOI: http://dx.doi.org/10.22159/ajpcr.2020.v13i6.37327

\section{INTRODUCTION}

Poisoning is a universal serious health problem that interferes with the well-being of human populations and one of the commonest cases admitted to the emergency department. Toxicity of poisons with suicidal tendency has become a health threat, particularly among adults.

Pesticide poisoning is a significant problem in India. Organophosphorus (OP) compounds cause most self-poisoning deaths in South India. Poisoning is an unnatural factor of morbidity and mortality commonly found in rural India [1]. Besides, it is reported that a significant number of suicide attempts in young people is frequently executed by drug overdose and observed more frequently in women [2]. It is also reported that $1-5 \%$ suicide attempts by drug overdose have resulted in death [3].

Poisoning is a diverse field that involves many pharmaceuticals, pharmacological, and chemical compounds in varied combinations [4]. Reducing deaths due to overdose require an effective medical management of acute poisoning. Accidental poisonings are more uncommon in this country than in developed countries. Senile mental confusion, diminished eyesight, and polypharmacy are the leading reasons for a high rate of accidental poisoning in adults.

The toxicity and fatality due to poisoning cases are more observed in developing countries when compared to developed countries [5]. It may be because of the availability of medical services, alcohol, and household chemicals, whereas in developing countries, the common causal agents are agrochemicals, including pesticides. The agricultural workers who often use toxic pesticides are the prime victims in such fatal poisonings [1].
According to the World Health Organization (WHO), death due to acute poisoning was about 45,000 per annum among youngsters $<20$ years and children under 6 years [6]. Intensive knowledge about the pattern of poisoning cases in this locality is more important for early diagnosis and prompt management [4]. However, new initiative steps are required to prevent poisoning using and storing medicines exactly as the label instructs. Further, measures to be taken to improve the availability of antidotes that could benefit the outcome. Large scale studies are essential to investigate the national protocol for poisoning management and to determine the approaches employed depending on the type of poison and thereby to prevent deaths due to poisoning.

In developing nations like India, poisoning is one of the most common causes of mortality due to the expanded use of chemicals in commercial, occupational, and domestic purposes and advent of a newer variety of drug treatment and massive use of insecticides in agriculture. The information about the pattern of poisoning in an exceedingly explicit region can facilitate in early management of poisoning cases, thus declining the rate of mortality and morbidity. Data offered from our region with regard to acute poisoning in adults is limited. Hence, this present study was conducted to explore the nature of poisoning cases, the use of various toxic substances (poison) indulged, and the drug utilization pattern for the management of poisoning cases in the medical department.

\section{METHODS}

This present study was a medical record-based retrospective study conducted in the medicine department of a tertiary care teaching hospital in southern coastal town, Puducherry, over a period of $21 / 2$ year. The study includes 127 population aged 12 years or older who 
met the diagnostic criteria for poisoning and who were admitted to the medical intensive care unit. Patients who were discharged or who expired within $24 \mathrm{~h}$ of admissions were excluded from the study. The mean \pm standard deviation (SD) age was $26.06 \pm 11.72$ year and the average difference between the time of consumption and the time of admission of patients in the hospital was $2 \mathrm{~h}$ and $8 \mathrm{~min}$.

The primary data sources included the medical records department. The medical case record files of all the inpatients of the medicine department with poisoning case admission between the reference period from June 2011 to January 2014 were retrieved from the medical records section after obtaining approval from the institutional ethics committee. The poisoning cases were analyzed by the demographic profile, the manner of poisoning (accident or suicide attempt), the number and the type or name of pharmacological and chemical agents responsible for the poisoning, and the drugs utilized for the management of poisoning cases were recorded. The categorization of the cases, according to the manner of poisoning, was made based on the information available from the history given by the patient or from the relatives in the medical records.

Statistical analysis of the study data was performed with SPSS (Statistical Package for the Social Sciences) version 22.0 software package. The numerical data were presented as mean \pm SD and the categorical variables were expressed as number and percentage (\%). The numerical data were compared across the groups using Student's t-test. The categorical variables were compared with the Chi-square test. $\mathrm{P}<0.05$ was considered statistically significant.

\section{RESULTS}

In this present study, the mean \pm SD age is $26.06 \pm 11.72$ year and the average difference between the time of consumption and the time of admission of patients is $2 \mathrm{~h}$ and $8 \mathrm{~min}$. The study revealed that of 127 cases, 92 (72.44\%) were females, while 35 (27.56\%) were males. Females had outnumbered males grossly. The total suicide cases were $103(81.10 \%)$ and accidental cases were 24 (18.89\%). Among the 92 females, $74(80.43 \%)$ had attempted suicide, while the rest $18(19.56 \%)$ was accidental. Of 35 males, 29 (82.85\%) had attempted suicide, while the rest $6(17.14 \%)$ was accidental. In this present study, the maximum number of cases 56 (44.09\%) was observed in the age group of $12-24$ years followed by 33 (25.98\%) cases in 25-36 year age groups (Table 1).

Systemic poisons were ingested in 60 cases (47.24\%) which remains the most common type of poison consumed in our study that resulted in 51 cases of suicides and rest 9 cases were accidental. Among which benzodiazepines (diazepam - 15, clonazepam - 3 and alprazolam - 3) with total 21 cases (16.54\%) being the commonest sub-class in systemic poisons, followed by anti-psychotic drugs 13 cases $(10.24 \%)$ with all suicidal attempts and the least was anti-histaminics with 2 cases $(1.57 \%)$. The second most common group involved in poisoning was irritants consisting of 28 cases $(22.05 \%)$, in which ant killer poison 10 cases $(7.87 \%)$ was highly consumed for suicide followed by 9 cases $(7.08 \%)$ of rat killer poison and 6 cases (4.72\%) of mosquito repellent liquid and the least was OP poison with 3 cases $(2.36 \%)$. Furthermore, the next poison group here was chemicals - $25(19.69 \%)$, in which vasmol dye poison with 15 cases $(11.81 \%)$ was frequently consumed, followed by the HIT solution with 8 cases $(6.30 \%)$ where these two poisons accidentally consumed by one case $(7.14 \%)$ and another had been the suicidal case, the least consumed was Harpic liquid with 2 cases (1.57\%) (Table 2).

Petroleum products such kerosene and diesel were the other groups with 11 cases (8.66\%), where 9 cases were suicides (7.96\%) and only 2 cases were accidental (14.29\%), which is further followed by a plant product group which consist of Nerium odorum in 2 cases (1.57\%) where one each was suicidal and accidental. The final poison group was unknown with 1 case was suicidal $(0.79 \%)$. This sums up a total of 113 attempted suicide cases and 14 cases were accidental (Table 2).
A total of 862 drugs were prescribed to 127 poisoned cases in our study, with a mean \pm SD of $86.2 \pm 75.47$ (Fig. 1).

According to various categories of drugs classified, intravenous fluids were the most commonly prescribed drugs $(n=213 ; 24.70 \%)$ with a mean \pm SD of $53.25 \pm 24.94$ (Fig. 1). Among the intravenous fluids, normal saline $(\mathrm{n}=83 ; 38.97 \%)$ was the most commonly prescribed drug followed by dextrose normal saline $(\mathrm{n}=61 ; 28.64 \%)$ and later by ringer lactate $(\mathrm{n}=55 ; 25.82 \%)$ while the least prescribed intravenous fluid was Isolyte-P $(\mathrm{n}=14 ; 6.57 \%)$ (Table 3 ).

The next most commonly prescribed group was general measures ( $\mathrm{n}=210 ; 24.36 \%$ ) with a mean \pm SD of $35 \pm 31.68$, of which gastric lavage $(\mathrm{n}=80 ; 38.1 \%)$ has been the most frequently used, followed by the other two measures, namely activated charcoal ingestion ( $n=72$; $34.29 \%)$ and Ryle's tube procedure $(n=41 ; 19.52 \%)$. The least used measure was calcium gluconate $(n=4 ; 1.91 \%)$ for the management of hypocalcemia or increased blood potassium or magnesium toxicity in this category (Table 4).

Anti-ulcer drugs $(\mathrm{n}=168 ; 19.49 \%)$ with a mean $\pm \mathrm{SD}$ of $33.6 \pm 26.97$ was the next major drug category prescribed to the poisoning cases, among which injection pantoprazole $(\mathrm{n}=85 ; 50.6 \%)$ was the most commonly prescribed drug followed by injection ranitidine $(n=36 ; 21.43 \%)$, one of the most common anti-ulcer drug used in day to day practice, followed by syrup sucralfate $(\mathrm{n}=19 ; 11.31 \%)$ and syrup antacid $(\mathrm{n}=16 ; 9.52 \%)$ and the least given drug was tablet pantoprazole $(n=12 ; 7.14 \%)$.

The next most commonly prescribed drug category was anti-emetic drugs $(n=61 ; 7.08 \%)$ with a mean \pm SD of $15.25 \pm 15.24$. Among them, injection ondansetron $(\mathrm{n}=41 ; 67.21 \%)$ was the most frequently prescribed drugs followed by parenteral metoclopramide $(\mathrm{n}=12$; $19.67 \%)$.

Table 1: Distribution of the study population according to age, sex, and manner of poisoning

\begin{tabular}{llll}
\hline Age groups (y) & Accidental n (\%) & Suicidal n (\%) & Total n (\%) \\
\hline Age groups & & & \\
12-24 & $9(16.21)$ & $47(83.78)$ & $56(44.09)$ \\
$25-36$ & $6(18.18)$ & $27(81.81)$ & $33(25.98)$ \\
$37-48$ & $4(20.00)$ & $19(80.00)$ & $23(18.11)^{*}$ \\
$49-60$ & $3(28.57)$ & $7(71.42)$ & $10(7.87)$ \\
$>60$ & $2(33.33)$ & $3(66.67)$ & $5(3.94)$ \\
Gender & & & \\
$\quad$ Female & $18(19.56)$ & $74(80.43)$ & $92(72.44)$ \\
Male & $6(17.14)$ & $29(82.85)$ & $35(27.56)$ \\
Total & $24(18.89)$ & $103(81.10)$ & $127(100)$ \\
\hline
\end{tabular}

Significant level $*$ if $\mathrm{p} \leq 0.05$

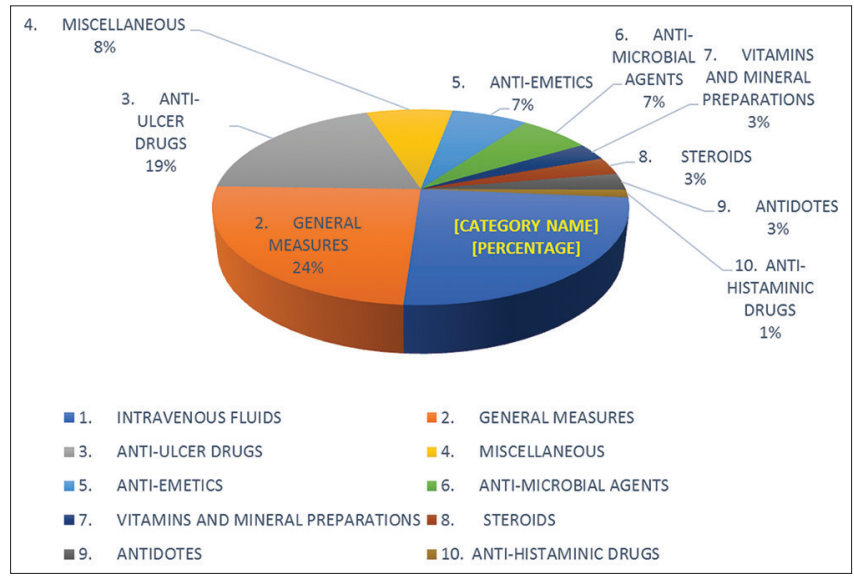

Fig. 1: Category-wise total drug prescribed 
Table 2: Distribution of the study population according to the type of poisoning

\begin{tabular}{|c|c|c|c|c|c|c|}
\hline \multirow{2}{*}{$\begin{array}{l}\text { Type of poisoning } \\
-n(\%)\end{array}$} & \multirow[t]{2}{*}{ Poison sub-type (n) } & \multicolumn{3}{|c|}{ Overall cases n (\%) } & \multicolumn{2}{|c|}{ Manner of poisoning $\mathrm{n}(\%)$} \\
\hline & & Total & Male & Female & Suicidal & Accidental \\
\hline \multirow[t]{7}{*}{$\begin{array}{l}\text { Systemic poisons }-60 \\
(47.24)\end{array}$} & $\begin{array}{l}\text { Benzodiazepines (Diazepam - 15, } \\
\text { Clonazepam, - 3, Alprazolam - 3) }\end{array}$ & $21(16.54)$ & $6(9.68)$ & 15 (23.08) & $\begin{array}{l}17 \\
(15.04)\end{array}$ & $4(28.57)$ \\
\hline & $\begin{array}{l}\text { Anti-psychotics (Risperidone }-6 \text {, } \\
\text { Olanzapine }-4 \text {, Chlorpromazine }-3 \text { ) }\end{array}$ & $13(10.24)$ & $12(19.35)$ & $1(1.54)$ & $\begin{array}{l}13 \\
(11.50)\end{array}$ & 0 \\
\hline & $\begin{array}{l}\text { Analgesics (Paracetamol }-5 \text {, } \\
\text { Aceclofenac }-2 \text {, Diclofenac }-1 \text { ) }\end{array}$ & $8(6.30)$ & $1(1.61)$ & 7 (10.77) & $8(7.08)$ & 0 \\
\hline & $\begin{array}{l}\text { Alcohol (Ethanol and Spirit }-4 \text {, } \\
\text { Liniments }-2 \text {, Cologne }-1 \text { ) }\end{array}$ & $7(5.51)$ & $5(8.06)$ & $2(3.08)$ & $6(5.31)$ & $1(7.14)$ \\
\hline & Levothyroxine & $5(3.94)$ & $2(3.23)$ & $3(4.62)$ & $4(3.54)$ & $1(7.14)$ \\
\hline & Multi-vitamins & $4(3.15)$ & 0 & $4(6.15)$ & $1(0.88)$ & $3(21.43)$ \\
\hline & $\begin{array}{l}\text { Antihistamine: (Chlorpheniramine } \\
\text { maleate) }\end{array}$ & $2(1.57)$ & 0 & $2(3.08)$ & $2(1.77)$ & 0 \\
\hline \multirow[t]{4}{*}{ Irritants - 28 (22.05) } & $\begin{array}{l}\text { Ant poison (Pyrethroid + permethrin } \\
+ \text { cypermethrin + tetramethrin }+ \\
\text { imiprothrin) }\end{array}$ & $10(7.87)$ & $7(11.30)$ & $3(4.62)$ & $10(8.85)$ & 0 \\
\hline & $\begin{array}{l}\text { Rat poison (Warfarin + sodium } \\
\text { borate }+ \text { strychnine }+ \text { bromethalin }+ \\
\text { aluminum phosphides) }\end{array}$ & $9(7.08)$ & $7(11.30)$ & $2(3.08)$ & $9(7.96)$ & 0 \\
\hline & $\begin{array}{l}\text { Mosquito repellents (Dimethyl } \\
\text { phthalate and N,N-diethyl-m- } \\
\text { toluamide) }\end{array}$ & $6(4.72)$ & $3(4.84)$ & $3(4.62)$ & $6(5.31)$ & 0 \\
\hline & Organophosphorus poison & $3(2.36)$ & 0 & $3(4.62)$ & $3(2.59)$ & 0 \\
\hline \multirow[t]{3}{*}{$\begin{array}{l}\text { Chemicals - } 25 \\
(19.69)\end{array}$} & $\begin{array}{l}\text { Vasmol (paraphenylene diamine, } \\
\text { resorcinol, PEG, sodium EDTA) }\end{array}$ & $15(11.81)$ & $6(9.68)$ & 9 (13.85) & $\begin{array}{l}14 \\
(12.39)\end{array}$ & $1(7.14)$ \\
\hline & HIT (Transfluthrin) & $8(6.30)$ & $6(9.68)$ & $2(3.08)$ & $7(6.19)$ & $1(7.14)$ \\
\hline & Harpic $(\mathrm{HCl}+$ butyl oleylamine $)$ & $2(1.57)$ & $1(1.61)$ & $1(1.54)$ & $2(1.77)$ & 0 \\
\hline Petroleum products & Kerosene and diesel & $11(8.66)$ & $6(9.68)$ & $5(7.69)$ & $9(7.96)$ & $2(14.29)$ \\
\hline Plant product & Nerium odorum & $2(1.57)$ & 0 & $2(3.08)$ & $1(0.88)$ & $1(7.14)$ \\
\hline Unknown & Cattle feeds ?? & $1(0.79)$ & 0 & $1(1.54)$ & $1(0.88)$ & 0 \\
\hline Total & & $127(100)$ & $62(100)$ & $65(100)$ & $113(100)$ & $14(100)$ \\
\hline
\end{tabular}

Table 3: Total percentage of intravenous fluids prescribed

\begin{tabular}{ll}
\hline Drugs & Total number (\%) \\
\hline NS & $83(38.97)$ \\
DNS & $61(28.64)$ \\
RL & $55(25.82)$ \\
Isolyte-P & $14(6.57)$ \\
Total & $213(100)$ \\
\hline
\end{tabular}

Among the antimicrobial agents (AMA) $(n=56 ; 6.50 \%)$ with a mean \pm SD of $7 \pm 3$, the most frequently prescribed drug was injection cefotaxime $(\mathrm{n}=14 ; 25 \%)$, followed by parenteral gentamicin $(\mathrm{n}=9 ; 16.07 \%)$ and the least prescribed AMA was injection amoxicillin ( $\mathrm{n}=4 ; 7.14 \%)$.

Injection Vitamin B complex $(n=17 ; 68 \%)$ with a mean \pm SD of $12.5 \pm 4.5$ was the most common vitamin supplemented to the poisoned cases, whereas injection hydrocortisone was the most frequently used steroid preparation $(\mathrm{n}=19 ; 76 \%)$.

Many antidotes were also used in these patients, in which injection atropine $(n=09 ; 37.5 \%)$ with a mean \pm SD of $4.8 \pm 2.4$ was the most used drugs followed by injection Vitamin $\mathrm{K}(\mathrm{n}=05 ; 20.83 \%)$ (Table 6).

The only used antihistaminic drug was chlorpheniramine maleate ( $n=11$; overall drugs $=1.28 \%$ ) with a mean \pm SD of $5.5 \pm 0.5$ (Fig. 1 ).

\section{DISCUSSION}

This current study involved the evaluation of medicine department medical records of poisoning episodes from different age groups. Similar to many previous studies, our study found that the majority of the poisoning cases were involved in younger age groups and in women $[4,7-10]$.
Table 4: Total percentage of general measures

\begin{tabular}{ll}
\hline Drugs & Total number (\%) \\
\hline Gastric lavage & $80(38.1)$ \\
Activated charcoal & $72(34.29)$ \\
Ryle's tube & $41(19.52)$ \\
Oxygenation & $8(3.81)$ \\
Salt water & $5(2.38)$ \\
Calcium gluconate & $4(1.91)$ \\
Total & $210(100)$ \\
\hline
\end{tabular}

It is been reported that the majority of poisonings (81.10\%) occurred in a suicide attempt, especially more in females compared to male [11]. Wang et al. advocated that the number of suicide attempts peaks, especially in seasons when the atmospheric pressure and temperature are high [8]. The differences in the rate of suicide attempts may be attributed to many factors, including seasonal characteristics, differences in socioeconomic level, increasing unemployment rates, and increasingly oppressive attitudes toward women.

Among all agents causing poisoning, benzodiazepines (16.54\%) had been frequently ingested for suicide attempts, which is consistent with other studies of Sorodoc et al., reported that the poisoning incidents most commonly observed with benzodiazepines (13.69\%) [9]. Most hypnotic sedatives are considered to be relatively safe. Another study also revealed the use of benzodiazepines (10.5\%) was responsible for suicides [12]. To our contradiction, a study revealed that no case in their study was involved an individual taking hypnotic sedatives [13]

This drug is followed by the use of antipsychotics (10.24\%) which is almost parallel to a study conducted by Jason and Robert, which suggested that antipsychotic drugs are responsible for $10.5 \%$ cases [12]. These results suggest that the prescription-free sales of benzodiazepine 
Table 5: Total percentage of miscellaneous drugs prescribed

\begin{tabular}{ll}
\hline Drugs & Total number (\%) \\
\hline Analgesics & $33(47.83)$ \\
Antidepressant drugs & $11(15.94)$ \\
Sedatives & $7(10.14)$ \\
Diuretics & $6(8.7)$ \\
Antihypertensive drugs & $5(7.25)$ \\
Laxatives & $3(4.35)$ \\
Antiepileptic drugs & $3(4.35)$ \\
Anti-asthma drugs & $1(1.45)$ \\
Total & $69(100)$ \\
\hline
\end{tabular}

Table 6: Total percentage of antidotes prescribed

\begin{tabular}{ll}
\hline Drugs & Total number (\%) \\
\hline Inj. atropine & $9(37.5)$ \\
Inj. Vitamin K & $5(20.83)$ \\
Inj. potassium chloride & $5(20.83)$ \\
Inj. acetylcysteine & $3(12.5)$ \\
Inj. pralidoxime & $2(8.33)$ \\
Total & $24(100)$ \\
\hline
\end{tabular}

Inj. = Injection

which are commonly branded as sleep medications and anti-psychotics that are usually known as stress-busters, at a lower price and a wider availability through pharmacies were broadly used and emotional fluctuation of patients treated with these drugs increases the risk of suicide attempts or poisoning.

In a study by Lund et al. reported that $18 \%$ of the cases occurred with ethanol and $15 \%$ with benzodiazepines [14], wherein our study, only $7 \%$ alcohol was consumed by the poisoned cases, which is inconsistent with few studies that the rate of alcohol-induced poisoning ranges only from $0.9 \%$ to $2.69 \%$ in different regions of middle eastern countries $[7,15]$.

Analgesics (6.3\%) were subsequently frequently consumed drug which was very less in comparison to Koylu et al. reported a rate of $57.2 \%$ for analgesic induced poisoning [16] and Goksu et al. reported a rate of $42.4 \%$ for analgesic-induced poisoning [17], whereas our report was not in line with a study conducted by Avsarogullari et al. found that $18.5 \%$ of patients were poisoned by antidepressants and $16 \%$ by analgesics [7]

Among the analgesics, the rate of poisoning caused by paracetamol was high in our study, which was consistent with a study done by Thomas et al., where paracetamol is the most common poisoning agent in England and the neighboring regions [18]. Hawton et al. reported that the rate of paracetamol as a cause of poisoning has recently increased [19]. This can be due to the wider use of paracetamol for secondary gain that the drugs are associated with the lowest fatality in a lower cost and prescription-free sales of these may clarify our findings.

In our present study, the corrosive agents such as irritants (22.05\%) and chemicals (19.69\%) induced poisoning were very high following the systemic poisons. As reported by some studies, it was far less seen in corrosive-induced poisoning rates as $4 \%$ and $5.4 \%$, respectively $[7,15]$. Since corrosive agents are found in houses as rodent killers, pesticides, and cleaning agents, also they are being cheap and widely available and sometimes stored in water or beverage bottles where one may be got drunk mistakenly. Therefore, corrosive-induced poisoning is one of the most common forms of poisonings.

Among the irritants induced poisoning, ant killer was consumed in the majority of cases, which is inconsistent with some previous studies, where organophosphates and agrochemical pesticides were the most common poisoning [20]. The role of natural pesticides was also assessed by some studies to replace dreadful agrochemical pesticides [21].
Petroleum products like petrol were very less consumed in our study, whereas a study on childhood poisoning in Nigeria reported kerosene as the common poison [22].

Various drugs were used in the management of poisoning. Symptomatic and supportive care was the mainstay of management in the majority of poisoning cases in our present study. Of which intravenous fluids $(24.7 \%)$ were the most frequently used drug for severely poisoned cases followed by dextrose normal saline to restore the life-threatening dehydration and electrolyte imbalance occurring in poisoned cases as early as possible.

The priority must be prevention of further absorption and the increase in poison elimination. Krenzelok and Dunmire recommended the use of gastric lavage, activated charcoal, and cathartics as needed in life-threatening cases [23]. In our study, gastric lavage (38.1\%) and activated charcoal (34.29\%) were the most employed measures, which are in accordance with earlier studies of Ardagh and Balasingam, reported that gastric lavage and activated charcoal were used at rates of $5 \%$ and $52 \%$, respectively [24]. Weir and Ardagh reported use of gastric decontamination using normal saline in $61 \%$ and activated charcoal use in 54\% [25]. Koylu et al. reported use of gastric lavage and activated charcoal at a rate of $50.7 \%$ [16]. Very liberal use of these measures may be because the patients did not specify the exact time they consumed the agent or gave an inconsistent history.

Those patients who present within $1 \mathrm{~h}$ of ingestion, may benefit from gastric decontamination, but currently, there is no evidence of clinical benefit. Furthermore, gastric lavage can be dangerous when performed without intubation in patients at risk of seizures or rapid loss of consciousness [26]. Diazepam or phenobarbitone should usually be sufficient to control seizures from pesticide poisoning, although patients with severe organochlorine poisoning may require general anesthesia. The value of prophylactic anticonvulsant therapy is not yet clear [27].

Adequate oxygenation was started in the required patients. Anti-ulcer drugs were used predominantly, especially proton pump inhibitors and $\mathrm{H} 2$-receptor blockers to prevent gastric erosion and to reduce excess gastric acid secretion, which is parallel to a previous study by Kishore et al. and Aravind and Rai [28,29]. Anti-emetics like ondansetron were also used when required, along with prophylactic use of AMA such as cefotaxime.

One of the mainstays of the pharmacological approach to the poisoning cases is antidotes such as atropine and pralidoxime in OP poisoning, Vitamin K against rat killer poisoning, and acetylcysteine for paracetamol poisoning which were used. These values were similar to many previous studies which reported that antidotes such as atropine, glycopyrrolate, pralidoxime, and acetylcysteine were commonly used in paracetamol and OP poisoning [29,30].

The doses of atropine used may have been appropriate in many cases - it is not possible to determine retrospectively from the notes how successful the atropine dosing was. Pralidoxime is a cholinesterase reactivator that also increases the rate of elimination of OP [31]. However, there is no hard evidence that oximes produce clinical benefit as of now [32]. Furthermore, recent Indian studies suggest that low doses of oximes may be harmful to patients [33]. The study confirms the very fact that the prevention and treatment of poisoning should merit a high priority within the healthcare of the local population.

In addition to these managements, AMA was also used. The most frequently prescribed antimicrobials in our present study have been third-generation cephalosporin like cefotaxime followed by gentamicin and ampicillin which stands consistent with antimicrobial usage reported by Aravind and Rai, [29]. Antimicrobials are irrationally used in low- and middle-income countries which are a massive global issue [34]. The WHO estimates that more than half of all medicines 
are prescribed, dispensed, or sold inappropriately [35]. Antibiotic resistance stands a serious threat to humans and undermines the global economy. Various clinical trials did not prove any benefit of antibiotic therapy in acute poisonings, especially in organophosphate poisoning [36].

\section{CONCLUSION}

Intentional drug overdosing is the significant hallmark of poisoningrelated fatality in South India. This occurrence may be linked to the domestic availability of common medications and also prescription free drug sale in pharmacies in our country. Inadequate social support, family conflicts, social isolation, unemployment, interpersonal relationships, and poor school merits could be some reasons associated with suicide attempts.

There are limitations to the retrospective study since the factors that favor to predict overall poisoning related fatality have been rarely elucidated. Although the incidence of poisoning is tough to estimate accurately, the huge availability and accessibility of chemical substances and their enormous use have expanded the threat of poisoning. We must identify the parameters that can help risk stratification and detection of high-risk patients, which are very important in the provision of health care with the limited resources in emergency departments.

Regular update of epidemiology data to detect trends for specific agents and to identify risk factors is necessary to enable clinicians, public health professionals, and the general public construct preventive strategies in treating such patients. Large scale studies are required to research on countrywide trends of poisoning and elements related to poisoning. Organizing a public health orientation program could raise awareness in our community that may help foster the development and application of appropriate solutions. It is suggested that a poison center in tertiary care hospitals will also help decrease morbidity and mortality. Family-oriented shielding approaches, school primarily based preventive programs and new legal rules and regulations on drug safety could also assist to scale back the frequency of suicide attempts.

\section{ACKNOWLEDGMENTS}

The author would like to thank the head of an Institution, Faculty Staff of Medicine and Pharmacology of Medical College, Puducherry, for their valuable help and support during this study.

\section{AUTHORS' CONTRIBUTIONS}

The author declares that this work done by the author mentioned in this article.

\section{CONFLICTS OF INTERSET}

I declare that there are no conflicts of interest.

\section{AUTHORS' FUNDING}

The author bears the publication fee of this paper.

\section{REFERENCES}

1. Batra AK, Keoliya AN, Jadhav GU. Poisoning: An unnatural cause of morbidity and mortality in rural India. JAP 2003;51:955-60.

2. Borowsky IW, Ireland M, Resnick M. Adolescent suicide attempts: Risks and protectors. Pediatrics 2001;107:485-93.

3. Hacker K, Collins J, Gross-Young L, Almeida S, Burke N. Coping with youth suicide and overdose: One community's efforts to investigate, intervene, and prevent suicide contagion. Crisis 2008;29:86-95

4. Lam SM, Lau AC, Yan WW. Over 8 year experience on severe acute poisoning requiring intensive care in Hong Kong, China. Hum Exp Toxicol 2010;29:757-65.

5. Sencan A, Adanir T, Aksun M, Karahan N, Anan G. The relationship of demographic and etiological characteristics with mortality in acutely poisoned patients admitted to intensive care unit. Turk Anesth Rean Der Dergisi 2009;37:80-5.
6. Mowry JB, Spyker DA, Cantilena LR Jr., Bailey JE, Ford M. Annual report of the American association of poison control centers' national poison data system (NPDS): $30^{\text {th }}$ annual report. Clin Toxicol (Phila) 2013;51:949-1229.

7. Avsarogullari L, Senol V, Akdur O, Akin A, Durukan P, Ozkan S. Characteristics of acute adult poisonings in a university hospital emergency department in central Turkey: A three-year analysis. J Pak Med Assoc 2012;62:129-33.

8. Wang YY, Wang D, Wang XY. Suicide and meteorological factors in Huhhot, Inner Mongolia. Crisis 1997;18:115-7.

9. Sorodoc V, Jaba IM, Lionte C, Mungiu OC, Sorodoc L. Epidemiology of acute drug poisoning in a tertiary center from Iasi county, Romania. Hum Exp Toxicol 2011;30:1896-903

10. Pathan AK, Dileep CM, Manoj KM, Sarah NB. A study on treatment pattern and outcomes of poisoning cases in a tertiary care and government district hospital. Int J Pharm Pharm Sci 2017;9:193-7.

11. Reddy S, Revathi D, Prasanna VL, Ramesh AC. Sociodemographic profile of patients with acute poisoning in the emergency wards of a tertiary care hospital. Int J Pharm Pharm Sci 2018;10:50-6.

12. Jason B, Robert SH. Hoffman: General management of poisoned patients. In: Tintinalli JE, Kelen GD, Stapczynski JS, editors. Emergency Medicine: A Comprehensive Study Guide. $6^{\text {th }}$ ed. New York: McGrawHill; 2004. p. 1015-22.

13. Lee HL, Lin HJ, Yeh ST, Chi CH, Guo HR. Presentations of patients of poisoning and predictors of poisoning-related fatality: Findings from a hospital-based prospective study. BMC Public Health 2008;8:7.

14. Lund C, Teige B, Drottning P, Stiksrud B, Rui TO, Lyngra M, et al. A one-year observational study of all hospitalized and fatal acute poisonings in Oslo: Epidemiology, intention and follow-up. BMC Public Health 2012;12:858.

15. Zöhre E, Ayrık C, Bozkurt S, Köse A, Narcı H, Cevik I, et al. Retrospective analysis of poisoning cases admitted to the emergency medicine. Arch Iran Med 2015;18:117-22.

16. Koylu R, Dundar ZD, Koylu O, Akinci E, Akilli NB, Gonen MO, et al. The experiences in a toxicology unit: A review of 623 cases. J Clin Med Res 2014;6:59-65.

17. Goksu S, Yildirim C, Kocoglu H, Tutak A, Oner U. Characteristics of acute adult poisoning in Gaziantep, Turkey. J Toxicol Clin Toxicol 2002; $40: 833-7$.

18. Thomas SH, Bevan L, Bhattacharyya S, Bramble MG, Chew K, Connolly J, et al. Presentation of poisoned patients to accident and emergency departments in the North of England. Hum Exp Toxicol 1996; $15: 466-70$

19. Hawton K, Harriss L, Hall S, Simkin S, Bak E, Bond A. Deliberate selfharm in Oxford, 1999-2000: A time of change in patient characteristics. Psychol Med 2003;33:987-95.

20. Singh B, Unnikrishnan B. A profile of acute poisoning at Mangalore (South India). J Clin Forensic Med 2006;13:112-6.

21. Gupta D, Sivadas S, Vikram K, Suneetha V. To assess the role of natural pesticides made from tulsi Ocimum tenuiflorum, turmeric Curcuma longa and neem Azadirachta indica on culinary crops and its maturing soil. Int J Appl Pharm 2016;8:13-5.

22. Adejuyigbe EA, Onayade AA, Senbanjo IO, Oseni SE. Childhood poisoning at the Obafemi Awolowo university teaching hospital, IleIfe, Nigeria. Niger J Med 2002;11:183-6.

23. Krenzelok EP, Dunmire SM. Acute poisoning emergencies. Resolving the gastric decontamination controversy. Postgrad Med 1992;91:17982, 185-6.

24. Ardagh M, Balasingam A. Trends in gastrointestinal decontamination for deliberate self-poisoning in Christchurch. N Z Med J 1996;109:1035, 462-3.

25. Weir P, Ardagh M. The epidemiology of deliberate self-poisoning presenting to Christchurch hospital emergency department. N Z Med J 1998:111:1063, 127-9.

26. Chyka PA, Seger D. Position statement: Single-dose activated charcoal. American academy of clinical toxicology and European association of poison centres and clinical toxicologists. J Toxicol Clin Toxicol 1997;35:721-41.

27. Rao CH, Venkateswarlu V, Surender T, Eddleston M, Buckley NA. Pesticide poisoning in south India: Opportunities for prevention and improved medical management. Trop Med Int Health 2005;10:581-8.

28. Kishore PV, Palaian S, Paudel R, Mishra D, Ojha P, Alam K, et al. Pattern of poisoning cases in a teaching hospital in Western Nepal. J Inst Med 2008;30:26-34.

29. Aravind A, Rai M. Pattern of acute poisoning admissions in the medical intensive care unit of a tertiary care hospital. Int J Pharm Sci Drug Res 2014;6:239-42. 
30. Abubakar S, Githa K, Kiran NE. A study on pattern of poisoning cases in a tertiary care hospital, Bangalore. Indian J Pharm Pract 2014;7:13-7.

31. Bismuth C, Inns RH, Marrs TC. Efficacy, toxicity and clinical uses of oximes in anticholinesterase poisoning. In: Clinical and Experimental Toxicology of Organophosphates and Carbamates. Oxford: Butterworth Heinemann; 1992. p. 555-77.

32. Eddleston M, Buckley NA, Checketts H, Senarathna L, Mohamed F, Sheriff $\mathrm{M}$, et al. Speed of initial atropinisation in significant organophosphorus pesticide poisoning--a systematic comparison of recommended regimens. J Toxicol Clin Toxicol 2004;42:865-75.

33. Samuel J, Peter JV, Thomas K, Jeyaseelan L, Cherian AM. Evaluation of two treatment regimens of pralidoxime (1 gm single bolus dose vs $12 \mathrm{gm}$ infusion) in the management of organophosphorus poisoning. J Assoc Physicians India 1996;44:529-31.

34. Afshari R. Non-medical use of medications in middle-and low-income countries. Asia Pac J Med Toxicol 2014;3:49.

35. Priyendu A, Vandana KE, Varma M, Prabhu N, Rahim AA, Nagappa AN. Antibiotic prophylaxis in organophosphorus poisoning: A study of health and economic outcomes. Saudi Pharm J 2017;25:332-6.

36. World Health Organization. The Pursuit of Responsible Use of Medicines: Sharing and Learning from Country Experiences. Geneva, Switzerland: World Health Organization Press; 2012. 